\title{
Contribuição à reflexão sobre a concepção de Natureza no ensino de Botânica
}

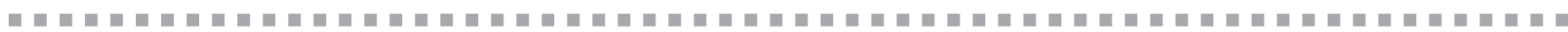

Lenir Maristela Silva

Valdo José Cavallet

Yedo Alquini

Palavras-chave: ensino de

botânica; ecologia; biologia da

conservação; didática; natureza.

\section{Resumo}

Discute sobre a visão da relação homem-natureza inerente ao ensino de Botânica e reflete sobre a concepção de Natureza a partir de uma leitura interpretativa de trabalhos, no contexto do ensino superior, dos anais dos Congressos Nacionais de Botânica do período de 1995 a 2002, sessão temática Ensino de Botânica. A análise infere que, para a melhoria do ensino de Botânica, na perspectiva da formação para a autonomia, é indispensável considerar o objeto de conhecimento em sua relação com a realidade concreta. Nesse contexto, incentivar apenas o uso de plantas nativas nas práticas pedagógicas e a preservação ambiental não é suficiente para formar acadêmicos aliados com a manutenção da diversidade biológica e com a conservação da diversidade cultural, pois há determinantes histórico-sociais que interferem nesse processo e que precisam ser considerados.

\section{Introdução e aspectos metodológicos}

Os fatos que nos remeteram a essa reflexão foram: a escassa produção científica na área Ensino de Botânica no Brasil, facilmente confirmada na consulta às bases de dados científicos e já denunciada por Marques (2000); a curiosidade em identificar quais sinais sobre a prática pedagógica do professor de Botânica de Ensino Superior estão impressos nos registros formais publicados nos meios científicos.

Para esclarecer como chegamos às reflexões a que remete o título deste trabalho, vamos traçar um pequeno relato histórico, pois este artigo é apenas parte de um trabalho mais amplo.
A busca por propostas publicadas para a melhoria do Ensino de Botânica revelou uma grande escassez de publicações, ou seja, encontramos um livro publicado (Pereira, Putzke, 1996) para o Ensino Fundamental e Médio e os resumos de trabalhos nos anais dos Congressos Nacionais de Botânica, organizados pela Sociedade Botânica do Brasil (SBB). Ao entrar em contato com alguns autores que publicaram nos congressos, por meio de correio eletrônico, na tentativa de conseguir trabalhos na íntegra, pudemos identificar que a única sistematização existente era sob a forma de resumo. Os periódicos da área de Botânica são completamente direcionados à pesquisa na área, o que inviabiliza publicações sobre a temática do ensino. Já os periódicos 
na área de educação apresentam discussões sobre didática, mas não encontramos nenhum que estabelecesse uma relação com a Botânica, apenas com as ciências de maneira geral e, mais especificamente, aquelas voltadas para o Ensino Fundamental ou Médio.

Luz (1982), ao propor um novo modelo de currículo para a área de Botânica na Universidade Federal do Paraná (UFPR), comenta sobre a defasagem existente entre o vulto de produção científica na área em relação à quase inexistência de trabalhos voltados para o processo ensino-aprendizagem desta. Decorridos mais de vinte anos, pouco se avançou.

Diante do exposto, escolhemos os Anais dos Congressos Nacionais de Botânica por representarem o maior espaço de divulgação, embora sintética, da produção dos botânicos brasileiros, na sua maioria, professores. Esses trabalhos revelam uma síntese da produção científica dos botânicos e, por que não dizer, uma expressão coletiva do pensamento dos Botânicos. Isso porque compreendemos a ciência numa perspectiva que não separa o sujeito que produz do objeto que é produzido. A partir disso, escolhemos a sessão temática que mais nos apresenta dados da prática pedagógica. Evidentemente, escolhemos a sessão Ensino de Botânica dentre outras sessões, tais como Florística e Fitossociologia, Sistemática e Evolução de Fanerógamas ou Botânica Estrutural.

Cabe uma consideração histórica acerca dessa sessão. O Ensino, como temática nos Congressos Nacionais de Botânica, principal evento oportunizado pela SBB, aparece pela primeira vez em 1982 na forma de tema de sessões técnicas e, posteriormente, de 1995 até o momento, numa sessão específica para a apresentação de trabalhos. Dos 127 trabalhos apresentados na temática Ensino de Botânica, de 1995 até 2002, aproximadamente 29\% (Tabela 1) enfocaram o ensino para a graduação. Os outros trabalhos, na maioria, enfocaram o ensino fundamental e médio e alguns apresentaram materiais didáticos que podem ser utilizados por diferentes públicos, como a constituição de catálogos, manuais, guias educativos para visitantes de jardins botânicos, avaliação de ciclo de espécies ou outros dados para integrar a Internet.

\section{Tabela 1 - Trabalhos sobre ensino de Botânica apresentados nos Congressos Nacionais de Botânica de 1995 a 2002}

\begin{tabular}{|c|c|c|}
\hline Ano & $\begin{array}{c}\text { Total de trabalhos sobre } \\
\text { o ensino de Botânica }\end{array}$ & $\begin{array}{c}\text { Trabalhos com enfoque } \\
\text { no ensino superior }\end{array}$ \\
\hline 2002 & 32 & 7 \\
\hline 2001 & 24 & 8 \\
\hline 2000 & 22 & 4 \\
\hline 1999 & 10 & 1 \\
\hline 1998 & 10 & 5 \\
\hline 1997 & 11 & 3 \\
\hline 1996 & 6 & 5 \\
\hline 1995 & 12 & 37 \\
\hline Total & 127 & 29,13 \\
\hline
\end{tabular}

Fonte: Construção realizada a partir dos Anais dos Congressos Nacionais de Botânica.

A partir disso, passamos a uma análise de cada um dos resumos incluídos no percentual de 29\%. Para essa análise, apontamos que a nossa orientação era o entendimento de que os sujeitos da prática educativa (professor e alunos) são sujeitos concretos, ${ }^{1}$ ou seja, que trazem uma visão de mundo e interesses próprios resultantes de suas condições de vida. Os interesses, por sua vez, são definidos pelas condições sociais concretas. O professor, estando a serviço do aluno concreto, visando à sua autonomia, em sua atividade pedagógica, precisa articular os conteúdos com a produção social global, possibilitando a apropriação do saber universal pelos alunos (Saviani, 1987; Vasconcellos, 
1992). Quando nos referimos à autonomia, falamos da capacidade de o sujeito determinar e escolher livremente os meios e os objetivos de seu crescimento intelectual bem como as formas de inserção no mundo social (Rodrigues, 2001).

Com essa fundamentação passamos à leitura interpretativa dos trabalhos selecionando algumas dimensões da prática docente, sendo elas: Como o ensino é considerado? Qual é o papel do professor? Qual é o papel do aluno? Qual consideração é dada ao objeto de conhecimento (conteúdo)? Essas dimensões foram escolhidas porque refletem dados do método de ensino ${ }^{2}$ implícitos nas sistematizações dos professores.

Ao realizarmos a análise das considerações dadas ao objeto de conhecimento, identificamos uma categoria muito importante nesse contexto, que é a concepção de natureza (ecossistemas de maneira geral) que têm os professores. A visão de mundo e de homem dos professores carrega uma compreensão dessa temática que acaba sendo explicitada em seu método de ensino e que, por sua vez, impregna sinais em suas sistematizações.

Evidentemente, as sistematizações nos trabalhos publicados nos anais dos Congressos Nacionais de Botânica não são o retrato fiel da prática pedagógica dos professores, pois esta envolve muitas variáveis. Contudo, são documentos muito importantes, pois consistem no material de mais fácil acesso para os professores que buscam informações sobre o ensino dessa ciência no Brasil.

Também não consideramos que esses documentos expressem a totalidade da concepção sobre natureza presente no ensino de Botânica, mas uma pequena parte que nos permite inferir interpretações que fomentem nossa reflexão nesse campo ainda pouquíssimo explorado.

Passamos, então, a apresentar o que nos revelou a análise da categoria concepção de natureza. Essa análise foi orientada por outras duas categorias: saber escolar e realidade concreta. A escolha dessas categorias é justificada na discussão.

\section{Reflexões sobre a concepção de natureza no ensino de Botânica}

A identificação da categoria concepção de natureza emergiu da análise das considerações dadas ao objeto do conhecimento ao identificarmos preocupações com a preservação ambiental e com a valorização das plantas nativas pelos que propõem melhorias para o ensino de Botânica.

Uma dessas preocupações é a utilização de plantas nativas da vegetação do cerrado e da floresta amazônica pelos professores de Morfologia Vegetal da Universidade de Brasília (UnB), como exemplos didáticos, diferenciando-se das espécies exóticas constantes em livros clássicos. Assim, para mostrarem endoderme com espessamento em U, eles utilizam raiz de Pterodon pubescen, que é nativa da região (Mendes, Ribeiro, 1996, p. 543). Conforme Mendes e Menezes-Neto (1998), o mesmo tipo de preocupação também aparece em relatos de professores de Morfologia Vegetal da Universidade Federal do Pará (UFPA). Similarmente, com o objetivo de estimular o conhecimento sobre a flora local e suas potencialidades econômicas e sociais, os professores de Sistemática da UFPA entendem como proposta de melhoria de ensino na graduação dos cursos de Biologia e Farmácia a criação de herbário didático com plantas regionais (Sablayrolles et al., 1998). Um outro trabalho propõe a adoção do pau-brasil (Caesalpina echinata Lam.) como um modelo para estudos morfológicos e anatômicos (Kraus et al., 2000, p. 194).

Nessa leitura, identificamos a categoria de análise saber escolar, que é inerente ao método de ensino. O objeto de conhecimento ou conteúdo consiste no que muitos autores denominam de saber escolar. Não se trata da transmissão pura e simples de saberes científicos, mas da seleção de determinados resultados científicos adequados à geração de aprendizagem, que não se esgota na aquisição de dados e informações (Vademarin, 1998).

Então, o saber escolar não pode ter como único componente o conhecimento científico e, além disso, se esse conhecimento é fragmentado, o saber escolar pretende ser justamente o contrário: a construção articulada dos dados do mundo, a fim de tornálos um todo coerente, compreensível às crianças, aos jovens e aos adultos (Vademarin, 1998).

Nesse contexto, ao demonstrarem a preocupação com os vegetais nativos, esses professores revelam fragmentos de como eles constituem o saber escolar, ou seja, esse saber constitui-se de algo além de uma mera listagem dos resultados da ciência Botânica que são dados de interesse histórico, social

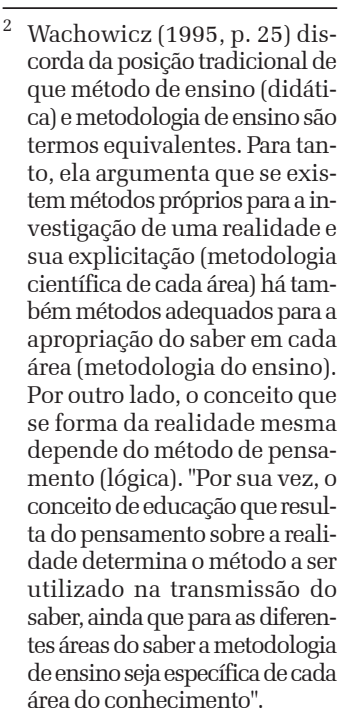


e ecológico. Esses dados são muito relevantes para o ensino de Botânica, pois o Brasil, embora detentor da maior biodiversidade do mundo, no que se refere à utilização dos vegetais na alimentação, tem a metade de sua energia alimentar baseada em três espécies exóticas: arroz, trigo e milho. A mandioca (Manihot sp.), que é originária do Brasil, contribui apenas com 7\% para a alimentação dos brasileiros (Wood, 1988).

Um dos determinantes dessa situação são as interferências internacionais que influenciam a política agrícola nacional. Dados sobre a América Latina demonstram em toda a região uma dependência alimentar externa e o agravamento do processo destrutivo dos recursos naturais, além da pobreza e exclusão dos camponeses (Chonchol, 1998).

Diante disso, considerando a formação para a autonomia, a escolha de quais espécies vegetais o professor de Botânica deve utilizar para suas aulas é muito importante, pois pode estar refletindo a reprodução das condições desejáveis a determinado grupo social. Esse grupo pode representar a hegemonia dominante em detrimento de uma população menos favorecida, como a dos pequenos agricultores, por exemplo. A mandioca citada acima é uma cultura muito mais comum nas pequenas propriedades rurais e nas comunidades tradicionais do que em grandes áreas de cultivo. Um dos reflexos da pouca consideração de comunidades, como a de pequenos agricultores, por exemplo, é o fato de a pesquisa aplicada à Produção Vegetal investir muitos recursos na adaptação de plantas exóticas monoculturáveis ao nosso ecossistema e raros recursos na domesticação de plantas nativas. Kageyama (1987) comenta que há pouco esforço na domesticação de novas espécies para a alimentação humana. Nesse contexto, um professor de Botânica para um Curso de Agronomia, por exemplo, que não considera esses determinantes sociais, possivelmente não estará contribuindo para uma formação para a emancipação.

Além desses aspectos, a utilização de plantas nativas para as aulas de Botânica deve ser estimulada por outros motivos. Um deles é que a introdução de plantas exóticas pode ter conseqüências benéficas, ou pode ocorrer o contrário, o que é mais comum, e cujos resultados nem sempre são previsíveis.
Há várias referências sobre plantas introduzidas que causaram grandes abalos em ecossistemas, como na Austrália, onde uma cactácea exótica (Prickly pear) invadiu milhões de hectares de hábitat nativo, transformando campos em bosques arbustivos impenetráveis, conseqüentemente, houve alteração/prejuízo de toda a fauna (Ricklefs, 1993).

Outro motivo é a incipiência de estudos de potenciais da nossa flora em nosso país, enquanto outros países contrabandeiam nossas espécies, estudam-nas e patenteiam seu uso, como é o caso de plantas utilizadas como fitoterápicos. Em uma lista inicial de matéria-prima explorada por outros países, aparece o rupununine, uma espécie de noz da Ocotea rodiei, usado como anticoncepcional. O extrato da espinheira-santa (Maytenus ilicifolia) já foi desenvolvido por uma empresa japonesa como medicamento contra gastrite. Além disso, a biopirataria não é apenas o contrabando de diversas formas de vida da flora e da fauna, mas, principalmente, a apropriação e a monopolização dos conhecimentos das populações tradicionais no que se refere ao uso dos recursos naturais (Biodiversidadla, 2003).

Evidentemente, é urgente a necessidade de conservação da biodiversidade, pois de aproximadamente 500 mil espécies vegetais existentes no mundo somente cerca da metade foi identificada (FAO, 1996), e desta, são escassos os estudos sobre Botânica, Ecologia, Fisiologia e da relação dessas espécies com as populações (Reis et al., 2002). Porém, é imprescindível que isso se dê de maneira sustentável, mas sustentável numa dimensão ambiental, social, econômica e política. Segundo Menezes (1998, p. 250), "restringir-se à dimensão ambiental condenaria a perspectiva da sustentabilidade ao mero conservacionismo".

Com esses fatos é possível argumentar que é muito importante, mas não é suficiente a inserção de dados relativos às plantas nativas na constituição do saber escolar para contribuir com a formação para a autonomia no ensino de Botânica. Isso porque a realidade concreta deve ser considerada, quando se pretende esse tipo de formação.

Temos, então, uma nova categoria para a análise e reflexão sobre a concepção de natureza no ensino de Botânica: a realidade concreta, que corresponde àquela que considera a sociedade dos homens de todas as regiões, portanto, uma realidade de dimensões econômica, política, social, cultural e 
de desenvolvimento técnico e científico. A realidade do sujeito corresponde àquela que considera as determinações sociais e históricas (Kosik, 1969; Morin, Kern, 2000).

Ou seja, o objeto de conhecimento ou conteúdo não pode ser considerado apenas pela aparência, mas também em essência e, portanto, não pode se constituir apenas de recortes fragmentados da realidade.

Chassot (1993), por exemplo, questiona o ensino de Química, quando os conteúdos são meramente um conjunto de símbolos, cálculos e conceitos distantes da realidade, ou seja, o ensino não cumpre sua função de compreensão da realidade. A discussão empreendida por Chassot (1993) pode ser extrapolada para grande parte dos conhecimentos ensinados nas Instituições de Ensino. A principal causa dessa situação é a excessiva especialização do conhecimento. É claro que a especialização é importante e necessária para o avanço e aprofundamento dos conhecimentos; todavia, o grande problema é a falta de articulação com a totalidade e a falta da visão de conjunto, tanto no problema investigado quanto na constituição do saber escolar. Com relação à ciência, Morin (1999) aponta que o afastamento do cotidiano tem sido criticado e apontado como a crescente superficialização da mesma.

Considerando que o saber escolar resulta de uma atividade complexa que recorta temas, seleciona conteúdos, propõe e avalia a execução de tarefas, propõe modelos de raciocínio e investigação, critica proposições existentes, dentre outras (Vademarin, 1998), se o professor não considera a realidade concreta, então o ensino, tal qual a ciência, também é excessivamente especializado.

Com isso, não estamos afirmando que o Ensino de Botânica não é contextualizado de modo geral, mas que a preocupação dos que ensinam e propõem melhorias para esse ensino deve ser orientada para uma ação educativa na perspectiva da concretude, para não inviabilizar a construção de pensamentos emancipatórios nos acadêmicos.

Por exemplo, uma expressão que se repetia e chamou a atenção na análise foi pressões antrópicas à natureza. Um dos trabalhos menciona o aprimoramento do ensino através da implantação de herbário e a justificativa da área de coleta escolhida é "devido às fortes ações antrópicas em regiões sob constante ameaça de devastação" (Santos et al., 1998 p. 297, grifo nosso).
Esse tipo de estudo tem todo o mérito na perspectiva da realidade concreta, pois revela a preocupação com a identificação de espécies antes que essas desapareçam. Sabemos que há uma aceleração no processo de desaparecimento da flora brasileira que não foi ainda sequer identificada. Por outro lado, generalizando, nos questionamos: será que os Professores de Botânica também não deveriam se preocupar com os determinantes sociais e históricos dessas pressões ou fortes ações antrópicas?

Uma justificativa para essa falta de contextualização relativa aos determinantes sociais e históricos da realidade é o próprio modelo curricular atual da maioria dos cursos de graduação e também dos cursos de ensino fundamental e médio que ainda são pautados na mera reprodução de conhecimentos. Especialmente no que se refere ao ensino de ciências, Krasilchic (2000) menciona que os currículos tradicionalistas-acadêmicos prevalecem no Brasil há muitas décadas, apesar das reformas e debates. $\mathrm{Ou}$ seja, persiste um currículo cujo objetivo é basicamente transmitir informação e no qual ao professor cabe apresentar a matéria de forma organizada e atualizada, facilitando a aquisição de conhecimentos. Essas matérias constituem-se dos resultados da Ciência da disciplina em questão.

Essa justificativa carrega em si uma outra que explica a própria formação dos professores de Botânica, ou seja, os professores atuais são fruto do mesmo modelo curricular.

Embora muitos professores de Botânica sintam-se justos ao defender a natureza das pressões antrópicas, talvez não estejam se dando conta de que revelam o oposto quando se mantêm restritos ao terreno especialista. Essa restrição pode desconsiderar as boas relações homem-natureza ou os determinantes sociais da má integração, causando uma discriminação sem o conhecimento de causa, ou seja, em muitas situações, a relação homem-natureza é a condição necessária à conservação da natureza.

No que se refere à formação escolar formal de muitos professores de Botânica, possivelmente a concepção de natureza advém dos conceitos inerentes à Ecologia, principalmente por ser uma área constante nos currículos de Ciências Biológicas e áreas afins. Segundo Diegues e Arruda (2001), a concepção de natureza que orienta a Ecologia ainda está bastante amparada nos princípios da Biologia da Conservação. Nessa 
abordagem, a preocupação central é com a biodiversidade no sentido de sua conservação, independente da contribuição que possa trazer aos humanos. Diegues faz extensa reflexão sobre a concepção histórica de natureza discutindo o significado de mito naturalista, diferindo mito da noção de falácia ou conhecimento equivocado. Ele argumenta:

A noção de mito naturalista, da natureza intocada, do mundo selvagem diz respeito a uma representação simbólica pela qual existiriam áreas naturais intocadas e intocáveis pelo homem, apresentando componentes num estado "puro" até anterior ao aparecimento do homem. Esse mito supõe a incompatibilidade entre as ações de quaisquer grupos humanos e a conservação da natureza. O homem seria, desse modo, um destruidor do mundo natural e, portanto, deveria ser mantido separado das áreas naturais que necessitariam de uma "proteção total." (Diegues, 2000, p. 53 , grifos do autor).

Essa visão meramente contemplativa da natureza foi determinada pela falta de integração entre as Ciências Naturais e as Ciências Humanas, o que, por sua vez, determinou que a Biologia desenvolvesse uma teoria conservacionista. Essa teoria surgiu na América do Norte e o Brasil importou modelos de conservação de áreas florestais fundamentadas nela. Esses modelos não admitem a presença de populações próximas e, no interior de áreas brasileiras protegidas, ou seja, consideram que toda relação entre sociedade e natureza é degradadora e destruidora do mundo natural e selvagem, sem que sejam feitas quaisquer distinções entre as várias formas de sociedade (a urbano-industrial, a tradicional, a indígena, dentre outras). Assim, todos os modos de vida deverão estar fora das áreas protegidas. No entanto, essas áreas encontramse em crise; muitas são invadidas e degradadas, principalmente, por empresários madeireiros. O modelo, criado no contexto ecológico e cultural norte-americano, não se aplica ao contexto dos países tropicais do Sul (Diegues, Arruda, 2001).

Esse modelo originou-se da racionalidade produtiva que, sem limites e referências gerais, tornou os ecossistemas sobrecarregados e insustentáveis por ignorarem as limitações geográficas e geológicas: "A decadência das economias do terceiro mundo no final da década de 80 fez que fracassasse o projeto de desenvolvimento econômico e agrícola e teve como conseqüência o êxodo rural e o superpovoamento das cidades e metrópoles" (Soares, 1996, p. 15).

Essa racionalidade produtiva esconde, por trás do discurso da preservação planetária, uma aposta de planificação globalizante da economia, impondo aos países pobres o ônus produtivo, bem como toda a carga dos detritos poluentes. Esse modelo sustentado por interesses complexos que são configurados, sobretudo, pelas grandes empresas sediadas nos países do Norte e cujas atividades se expandem para os países do Sul. Isso tem causado uma dependência financeira dos últimos e pelas políticas autoritárias de seus governantes, que foram educados sob a lógica economicista em detrimento das políticas sociais e ambientais que favoreçam os padrões razoáveis da vida planetária (Korb, Garcia, 2002).

Muitos autores, a partir da década de 80, vêm analisando os impactos sociais, ecológicos e culturais sobre as regiões de floresta tropical em diferentes continentes e começaram a enfatizar as causas do insucesso de muitas áreas protegidas. Esses autores partem da constatação de que muitas dessas áreas habitadas por populações tradicionais haviam se conservado sob cobertura florestal e com alta biodiversidade em virtude do manejo ligado ao modo de vida das comunidades que, com a criação das áreas protegidas, passaram a estar sujeitas à expulsão. Esses cientistas, ligados às ciências naturais e às sociais, construíram o que pode ser chamada de ecologia social ou ecologia dos movimentos sociais. Sob o ponto de vista ético, considera-se injusto expulsar comunidades que vivem em áreas de florestas desde gerações passadas e são responsáveis pela qualidade dos hábitats transformados em áreas protegidas, dado o seu modo de vida e o uso tradicional dos recursos naturais. Sob o ponto de vista político, constatou-se que, sem o apoio dessas comunidades, grande parte das ações conservacionistas e preservacionistas tem efeito oposto à real conservação dos hábitats e dos recursos naturais (Diegues, Arruda, 2001).

Tudo isso é reflexo do enfoque econômico, pois mesmo o discurso da sustentabilidade ambiental e da melhoria das condições de vida das populações pobres tem implícitos os interesses econômicos. Os incentivos dados pelo sistema financeiro internacional para o combate à pobreza a partir de 1992 visaram, através dos projetos do Banco Mundial, apenas 
amenizar as políticas excludentes oriundas do processo globalizante. Desse modo, a falsa ilusão promovida pela aparente melhoria na qualidade de vida, bem como os princípios de sustentabilidade, resultaram em práticas totalmente opostas às esperadas (Soares, 1996).

Quanto aos determinantes desse modelo, Diegues e Arruda (2001, p. 17) complementam:

O modelo de área natural desabitada interessa aos governos por duas razões: constituem reservas naturais de grande beleza cênica, de destino turístico e do chamado ecoturismo, e por que é mais fácil negociar contratos de uso da biodiversidade num espaço controlado pelo governo do que num espaço ocupado por comunidades tradicionais, pois, pelo art. $8^{\circ}$ j da CDB (Convenção sobre Diversidade Biológica), essas precisariam ser ressarcidas no momento em que seu conhecimento tradicional sobre espécies da flora fosse usado para obtenção de medicamentos e produtos.

Alguns exemplos, nos vários continentes, têm revelado que, quando é dado o apoio necessário às comunidades tradicionais, elas são as primeiras a mostrar oposição à degradação da natureza, em virtude dos efeitos devastadores das mineradoras, das madeireiras e dos especuladores. Não resta dúvida de que esse seja um dos desafios cruciais com que se defronta hoje a conservação no Terceiro Mundo (Diegues, 2002).

Recentes estudos indicam que, para o estabelecimento de estratégias que viabilizem o manejo sustentado de uma determinada espécie em seu ambiente natural, estão implicadas a recuperação e a sistematização de conhecimentos tradicionais (Reis, 1996). A maioria dos sistemas de manejo desenvolvidos e empregados por comunidades tradicionais contempla, de forma empírica, vários dos aspectos que favorecem a manutenção da estrutura das populações naturais sob extrativismo. Infelizmente, tal conhecimento vem se perdendo pelo desinteresse das gerações mais jovens e, principalmente, pelos processos de aculturação a que são submetidas tais comunidades. Além disso, em alguns casos, há uma apropriação da cultura das populações sem o retorno de melhoria das suas condições, o que é lamentável.

Esse pensamento está presente na argumentação de muitos intelectuais preocupados com o destino da humanidade, como expressa o manifesto surgido no Simposio sobre Etica e Desarollo Sustentable, ocorrido em maio de 2002 em Bogotá, na Colômbia:

La crisis ambiental es una crisis de civilización. Es la crisis de un modelo económico, tecnológico y cultural que ha depredado a la naturaleza y negado a las culturas alternas. El modelo civilizatorio dominante degrada el ambiente, subvalora la diversidad cultural y desconoce al Otro (al indígena, al pobre, a la mujer, al negro, al Sur) mientras privilegia un modo de producción y un estilo de vida insustentables que se han vuelto hegemónicos en el proceso de globalización (Manifiesto por la vida, 2002, p. 1).

Outra pista que nos chamou a atenção durante a análise foi a idéia de que os alunos precisam apreciar a beleza e gostar da natureza para preservar. Como ilustração, um trabalho apresentado no $46^{\circ}$ Congresso Nacional de Botânica descreve a realização de uma exposição comunitária mencionando que é uma tentativa de "explorar as características de beleza e harmonia das plantas, além da adaptabilidade ao meio, como um caminho natural: conhecer, gostar, preservar!" (Braga, 1995, p. 284, grifos nossos).

Novamente, não queremos tirar o mérito desse tipo de trabalho, mas sim argumentar que isso não é suficiente para formamos acadêmicos engajados na manutenção da diversidade biológica e na conservação da diversidade cultural, pois há determinantes sociais que interferem nesse processo e que merecem ser considerados. Por exemplo, se o leitor desse texto estivesse passando fome por estar desempregado e, ao lado da vila em que morasse houvesse uma reserva biológica, será que optaria por proteger e contemplar a beleza da natureza ao invés de suprir sua fome? Ou seja, a análise dos problemas ambientais não pode vir descolada da análise dos problemas sociais. É impossível solucionar problemas numa perspectiva reducionista, portanto, os professores de Botânica que tratam a questão da natureza apenas pela via da conservação, sem levar em conta os determinantes da degradação da natureza e os exemplos de boa integração homem-natureza, provavelmente, não poderão possibilitar aos alunos, futuros profissionais, uma apropriação de conhecimentos para a resolução de problemas da realidade concreta. Evidentemente, essa não deve ser uma responsabilidade apenas dos professores de 
Botânica, mas deles também: procurar fazer o possível dentro das inúmeras dificuldades de um modelo de currículo universitário ainda arcaico.

Além de ser responsabilidade do professor de Botânica dar conta de discutir o saber escolar numa perspectiva de concretude, há também a possibilidade de integração dos professores de diferentes áreas, a fim de minimizar a problemática da especialização que não dá conta de explicar a realidade.

Diegues (2000, p. 159), ao se referir à produção de conhecimento sobre a conservação da biodiversidade e sua proteção, argumenta que,

Até hoje, no Brasil, a avaliação de uma área a ser declarada unidade de conservação tem sido responsabilidade única dos cientistas naturais. É necessária uma visão interdisciplinar, onde trabalhem de forma integrada biólogos, engenheiros florestais, sociólogos, antropólogos e cientistas políticos, entre outros em cooperação com as populações tradicionais.

Essa argumentação é pertinente não só na perspectiva da produção do conhecimento, mas também na perspectiva das ações educativas neste país.

Para Capelletti (1992), uma formação restrita ao aspecto técnico científico tem acarretado também uma informação segmentada por superposição e/ou falta de conteúdos importantes para o profissional, o mesmo ocorrendo com a bibliografia e até com recursos instrucionais. Como conseqüência disso, também é restrita a comunicação entre professores de um mesmo curso. A riqueza da troca de experiências e das discussões curriculares é perdida.

A formação de uma equipe de trabalho de professores de um mesmo curso tem sido dificultada pela estrutura organizacional da universidade. Os professores são indicados pelo departamento e/ou chefes de disciplinas, sem que haja um espaço para trocas, discussões, acertos, perdendo-se de vista a interdisciplinaridade e o profissional que se está formando (Capelletti, 1992, p. 15).
Cavallet (1999) critica a separação entre a concepção e a execução da formação profissional universitária mencionando que na Agronomia, por exemplo, o contato entre os professores para o planejamento curricular é minimizado, dificultando o desenvolvimento de habilidades pedagógicas direcionadas a questionar as contradições da formação dos estudantes. Acrescenta que os professores, preocupados com a execução de suas disciplinas, mantêm distância do objetivo principal do curso no qual lecionam.

Morin (2001, p. 39) alerta que é preciso reformar o pensamento "para a formação de uma consciência humanística e ética de pertencer à espécie humana, que só pode ser completa com a consciência do caráter matricial da Terra para a vida, e da vida para a humanidade". Por sua vez, a universidade deve possibilitar a democratização do conhecimento para além de seus muros, integrar, no presente, valores transeculares e integrar prosa e poesia (Morin, Kern, 2000).

\section{Considerações finais}

Para melhoria do Ensino de Botânica, não podemos prescindir da reflexão e da auto-reflexão sobre a prática pedagógica e seus determinantes histórico-sociais. $\mathrm{Na}$ perspectiva da formação para a autonomia, é indispensável considerar o objeto de conhecimento na sua relação com a realidade concreta. Nesse contexto, para formamos acadêmicos aliados com a manutenção da diversidade biológica e com a conservação da diversidade cultural, não é suficiente incentivar o uso de plantas nativas e a preservação ambiental nas práticas pedagógicas, pois há determinantes histórico-sociais que interferem nesse processo e que precisam ser considerados.

Além disso, é importante ressaltar que o atual estudo, apesar de apenas introduzir o debate sobre a concepção de natureza no ensino de Botânica, pode possibilitar aos professores da área das Ciências Naturais uma análise sobre o fato de estarem contribuindo ou não para uma formação emancipatória. 


\section{Referências bibliográficas}

BIODIVERSIDADLA. Quanto valem a fauna e flora brasileiras? Disponível em: http:// www.biodiversidadla.org/article/articleview . Acesso em: 16 jun. 2003.

BRAGA, M. M. N. Anatomia Vegetal no curso de Ciências Biológicas da UFMG. In: CONGRESSO NACIONAL DE BOTÂNICA, 46., 1995, Ribeirão Preto (SP). Anais... Ribeirão Preto (SP): SBB, 1995. p. 284.

CAPELLETTI, I. F. A docência no ensino de $3^{\circ}$ grau. In: D'ANTOLA, A. (Org.). A prática docente na universidade. São Paulo: EPU, 1992. p. 13-26.

CAVALLET, V. J. A formação do Engenheiro Agrônomo em questão: a expectativa de um profissional que atenda as demandas sociais do século XXI. 1999. Tese (Doutorado em Educação) - Faculdade de Educação da Universidade de São Paulo, São Paulo, 1999.

CHASSOT, A. I. Catalisando transformações na educação. Ijuí: Ed. Unijuí, 1993. 174 p.

CHONCHOL, J. Prefácio. In: FERREIRA, A. D. D.; BRANDENBURG, A. (Org.). Para pensar outra agricultura. Curitiba: Ed. UFPR, 1998. p. 3-12.

DIEGUES, A. C. Aspectos sociais e culturais do uso dos recursos florestais da Mata Atlântica. In: SIMÕES, L. L.; LINO, C. F. (Org.). Sustentável Mata Atlântica: a exploração de seus recursos florestais. São Paulo: Ed. Senac, 2002. p. 135-158.

. O mito moderno da natureza intocada. 3. ed. São Paulo: HUCITEC, Núcleo de

Apoio à Pesquisa sobre Populações e Áreas úmidas Brasileiras, USP, 2000. 169 p.

DIEGUES A. C.; ARRUDA, R. S. V. (Org.). Saberes tradicionais e biodiversidade no Brasil. Brasília: Ministério do Meio Ambiente; São Paulo: USP, 2001. 176 p.

FAO. Comissión de Recursos Geneticos para la Alimentación y la Agricultura. Documento Informativo de Estúdios, n. 5, 1996.

KAGEYAMA, P. Y. Conservação "in situ" de recursos genéticos de plantas. IPEF, Piracicaba, n. 35, p. 7-37, abr. 1987.

KORB, A.; GARCIA, C. B. A questão ambiental: perspectivas políticas e educacionais. In: SEMINÁRIO ANPED-SUL, 4., Florianópolis. Anais: na contracorrente da Universidade operacional (com artigo completo). Florianópolis, 2002. 1 CD-ROM.

KOSIK, K. Dialética do concreto. Rio de Janeiro: Paz e Terra, 1969. 230 p.

KRAUS, J. E. et al. Brasil 500 anos do descobrimento: imagens do pau-brasil (Caesalpinia echinata Lam.). In: CONGRESSO NACIONAL DE BOTÂNICA, 51., 2000, Brasília (DF). Anais... Brasília (DF): SBB, 2000. p.194.

KRASILCHIC, M. Reformas e realidade: o caso do ensino de ciências. São Paulo em perspectiva, v. 14, n. 1, p. 85-93, 2000.

LUZ, G. O. F. da. Modelo de currículo para ensino de conjunto de disciplinas ofertadas pelo departamento de Botânica - UFPR. 1982. Dissertação (Mestrado em Educação) Universidade Federal do Paraná, Curitiba, 1982.

MANIFIESTO por la vida. Disponível em: http://www.rolac.unep.mx/educamb/esp/ mantexto.htm. Acesso em: 10 nov. 2002. 
MARQUES, M. O. Aprendizagem na mediação social do aprendido e da docência. Ijuí: Unijuí, 2000. 144 p.

MENDES, A. M. C. de M.; MENEZES-NETO, M. A. Práticas de Anatomia Vegetal: uma experiência com a utilização de plantas regionais e tropicais na Universidade Federal do Pará. In: CONGRESSO NACIONAL DE BOTÂNICA, 49., 1998, Salvador (BA). Anais... Salvador (BA): SBB, 1998. p. 298.

MENDES, I. C. A.; RIBEIRO, D. G. Aspectos estruturais de algumas espécies nativas utilizadas nas aulas práticas de Anatomia Vegetal do departamento de Botânica da Universidade de Brasília. In: CONGRESSO NACIONAL DE BOTÂNICA, 47., 1996, Nova Friburgo (RJ). Anais... Nova Friburgo (RJ): SBB, 1996. p. 543.

MENEZES, F. Sustentabilidade alimentar: uma nova bandeira? In: FERREIRA, A. D. D.; BRANDENBURG, A. (Org.). Para pensar outra agricultura. Curitiba: Ed. UFPR, 1998. p. 249-270.

MORIN, E. Ciência com consciência. 3. ed. Rio de Janeiro: Bertrand Brasil, 1999. 350 p.

. A cabeça bem-feita: repensar a reforma, reformar o pensamento. 3. ed. Rio de Janeiro: Bertrand Brasil, 2001. 128 p.

MORIN, E.; KERN, A. B. Terra-Pátria. 3. ed. Porto Alegre: Sulina, 2000. 192 p.

PEREIRA, A. B.; PUTZKE, J. Ensino de Botânica e ecologia: proposta metodológica. Porto Alegre: Sagra, DC Luzzatto, 1996. 184 p.

REIS, M. S. Manejo sustentado de plantas medicinais em ecossistemas tropicais. In: STASI, L. C. (Org.). Plantas medicinais: arte e ciência: um guia de estudo interdisciplinar. São Paulo: Unesp, 1996. p. 199-215.

REIS, M. S. et al. Aspectos do manejo de recursos da mata atlântica no contexto ecológico, fundiário e legal. In: SIMÕES, L. L.; LINO, C. F. (Org.). Sustentável Mata Atlântica: a exploração de seus recursos florestais. São Paulo: Ed. Senac, 2002. p. 159-171.

RICKLEFS, R. E. A economia da natureza. 3. ed. Rio de Janeiro: Guanabara Koogan, 1993. $470 \mathrm{p}$.

RODRIGUES, N. Educação: da formação humana à construção do sujeito ético. Educação $\mathcal{E}$ Sociedade, v. 22, n. 76, p. 232-257, 2001.

SABLAYROLLES, M. das G. P. et al. O herbário didático da UFPA; uma proposta de melhoria no ensino da Botânica na graduação. In: CONGRESSO NACIONAL DE BOTÂNICA, 49., 1998, Salvador (BA). Anais... Salvador (BA): SBB, 1998. p. 296.

SANTOS, M. C. F. dos et al. Aprimoramento do Ensino de Botânica através da implantação do herbário didático do curso de ciências biológicas da Faculdade de Formação de Professores - UERJ em São Gonçalo, RJ. In: CONGRESSO NACIONAL DE BOTÂNICA, 49., 1998, Salvador (BA). Anais... Salvador (BA): SBB, 1998. p. 297.

SAVIANI, D. Escola e democracia. 19. ed. São Paulo: Cortez, 1987. 103 p.

SOARES, M. C. C. Banco Mundial: políticas e reformas. In: DE TOMMASI, L.; WARDE, M. J.; HADDAD, S. (Org.). O Banco Mundial e as políticas educacionais. São Paulo: Cortez, PUC-SP, Ação Educativa, 1996. p. 15-40.

VADEMARIN, V. V. O discurso pedagógico como forma de transmissão do conhecimento. Cadernos CEDES, v. 19, n. 44, p. 73-84, 1998. 
VASCONCELLOS, C. Metodologia dialética em sala de aula. Revista da Educação AEC, n. 83, p. 28-52, 1992.

WACHOWICZ, L. A. O método dialético na didática. 3. ed. Campinas (SP): Papirus, 1995. $141 \mathrm{p}$.

WOOD, D. Introduced crops in developing countries: a sustainable agriculture? Food Policy, v. 13, p 167-177, 1988.

Lenir Maristela Silva, doutora em Produção Vegetal, na linha de pesquisa sobre o ensino de Agronomia, pela Universidade Federal do Paraná (UFPR), é professora de Botânica no Curso de Agronomia do Centro Federal de Educação Tecnológica do Paraná (Cefet/ Pr) - Unidade Sudoeste - Campus Pato Branco.

lenir@pb.cefetpr.br

Yedo Alquini, doutor em Botânica pela Universidade Estadual de São Paulo (USP), é professor de Morfologia Vegetal, Microtécnica e Fotomicrografia na Universidade Federal do Paraná (UFPR).

yedo@terra.com.br

Valdo Jose Cavallet, doutor em Educação pela Universidade Estadual de São Paulo (USP), é professor de Metodologia do Ensino de Ciências Agrárias na Universidade Federal do Paraná (UFPR) e pró-reitor de graduação na mesma instituição

cavallet@uol.com.br

\section{Abstract}

Contribuition to the reflection on the conception of Nature in the teaching of Botany

We discussed the man-nature relationship concerning the teaching of Botany. We reflected on the concept of Nature from an interpretative reading of some works, in the undergraduate context, which were taken from the Annals of the Botany National Congresses from 1995 to 2002, in the thematic section the Teaching of Botany. The analysis allows us to conclude that, to the improvement of teaching of Botany, from an autonomous educational perspective, it is fundamental to consider the object of knowledge in its relation with concrete reality. In this context, it is not sufficient to motivate the use of native plants in the pedagogic practices and the environmental preservation to form undergraduate students who are committed to the biological diversity maintenance and to the cultural diversity conservation, since there are some socio-historical determinants, which interfere in this process and need to be considered.

Keywords: teaching of botany; ecology; biology of conservation; didactic; nature. 